\title{
Epidemiological Study of Hydatidosis in Sheep Slaughtered at M'Sila Abattoirs (Algeria)
}

\author{
Samia HAFFAF ${ }^{1 *}$, Fatima Zahra RAGOUB ${ }^{1}$, Adel MAMMERI ${ }^{1}$, Zouina NOUARI ${ }^{1}$, Imen DJAALAB ${ }^{2}$, \\ Abdessalam ZERNINE ${ }^{3}$ \\ ${ }^{1}$ Department of Agronomic Sciences, Faculty of Sciences, University of M'Sila, 028000. Algeria. \\ ${ }^{2}$ Institute of Veterinary Sciences, University of Constantine 1, 025100, Algeria. \\ ${ }^{3}$ Veterinary Doctor, Directory of Veterinary Services, M'Sila, 028000, Algeria. \\ *corresponding author: samia.haffaf@univ-msila.dz
}

Bulletin UASVM Veterinary Medicine 77(2)/2020

Print ISSN 1843-5270; Electronic ISSN 1843-5378

doi:10.15835/buasvmcn-vm:2019.0040

\begin{abstract}
Hydatidosis is a parasitic disease caused by Echinococcus granulosus. It is also among the most prevalent zoonotic diseases with special importance for public health that causes drastic financial losses in both developed and developing countries. Among Algerian governorates, M'Sila region includes an important number of sheep flocks. Thus, an epidemiological survey was conducted on sheep hydatidosis during 5 months between December 2017 and April 2018 at three slaughterhouses of M'sila governorate, situated in municipalities of M'Sila, Boussaâda and Sidi Aissa. In parallel, an epidemiological investigation via interviews and questionnaire was conducted from March to April, 2018 on a sample of 46 sheep breeders located in M'Sila region. The questionnaire treated several risk factors (presence and deworming of dogs, informal slaughtering practices, fiability of preventive measures... etc.). Results showed a general prevalence of $24.80 \%$ among 9048 slaughtered sheep, and a seasonal prevalence higher in spring (42.02\%) than in winter $(21.65 \%)$ ( $p>0.05$ ). Sheep of five to six years old and more are the most parasitized $(\mathrm{p}<0.0001)$. The lungs (38. 24\%) and the livers (30.39\%) were the most affected organs, while $31.24 \%$ of sheep were affected simultaneously in both organs (liver and lungs). Furthermore, females are more affected $(97.99 \%)$ than males $(2.01 \%)(\mathrm{p}<0.0001)$.
\end{abstract}

Keywords: Epidemiological survey, sheep hydatidosis, Echinococcus granulosus, slautherhouses, Algeria.

\section{Introduction}

Sheep production is a major economic activity in arid and semi-arid regions of Algeria. However, it is threatened by several infectious and parasitic diseases. Hydatidosis, is a zoonotic disease caused by the cystic larval stage of the tapeworm Echinococcus granulosus. Hydatid cysts in livestock are diagnosed when animals are sent to abattoirs for slaughter (Thompson and Mc Manus, 2002). The normal life cycle of Echinococcus species requires two mammalian hosts; dogs and other canids are typical definitive hosts, while larval stages or the hydatid cyst occur in herbivorous intermediate hosts and, occasionally, in humans
(Melaku et al., 2012, Craig et al., 2015, Romig et al., 2015).

Hydatid cysts in intermediate hosts are normally asymptomatic, and there are usually no dependable methods for the routine diagnosis of the infection in living animals except in a few cases where cysts have been distinguished by ultrasonography (Eckert and Deplazes, 2004, Hayajneh et al., 2014).

The prevalence of cystic echinococcosis is higher in livestock animals in North Africa, in this region disease is endemic and home slaughter is practiced, and few abattoirs have sufficient veterinary supervision. Dogs are usually the main 
source of infection for livestock animals when they graze on contaminated pastures and get infected with the eggs of the parasite (Lahmar et al., 2013).

The lack of recent epidemiological data on hydatidosis and its economic and social impact in M'Sila region, has incited us to make this study. Its main objectives are : to estimate the prevalence of hydatid cysts in sheep comparatively at three local slaughterhouses; to study the predominant anatomical locations of Echinococcus granulosus, to highlight the influence of some risk factors in disease dissemination in study area, particularly those related to sheep hydatodosis as well as, animals age and sex and farms management methods.

\section{Material and methods Ethical approval}

The Ethical Committee of the Department of Agronomic Sciences of M'sila University (Algeria), approved all procedures of study. Autopsies for diagnosis were done only on slaughtered animals.

\section{Study area and survey locations}

The study area includes three municipalities of M'Sila governorate, including an important amount of sheep flocks (Figure 1).

The survey was conducted at three local slaughterhouses of M'Sila governorate (M'Sila,
Boussaâda and Sidi Aissa) over a period of 5 months from December 2017 to April 2018. Only large and small ruminants were slaughtered in the selected abattoirs.

\section{Animals and investigational design}

The investigation was done on 9048 slaughtered sheep ( 2478 males and 6570 females) aged between 1 and 6 years. These animals take origin from different municipalities of M'Sila governorate, nevertheless exact animals traceability was difficult to establish, due to; non identification of both flocks and breeders; the uncontrolled sales movement and informal animal markets especially for ruminants. Thus, regular weekly visits of 2-3 times, were accomplished in order to evaluate hydatidosis prevalence and the recovery of slaughter reports.

A questionnaire including fundamental risk factors, season, age and sex of animals was established. Sheep carcasses were examined by visual inspection and palpation for hydatid cysts in order to determine cysts number, types and their localizations in visceral organs including the liver, lungs, spleen, heart and kidneys, according to guidelines recommended by WHO (2011). To evaluate the intensity of infection, the number of cysts was counted per infected organ isolated from the sheep. Intensity of infection was divided into

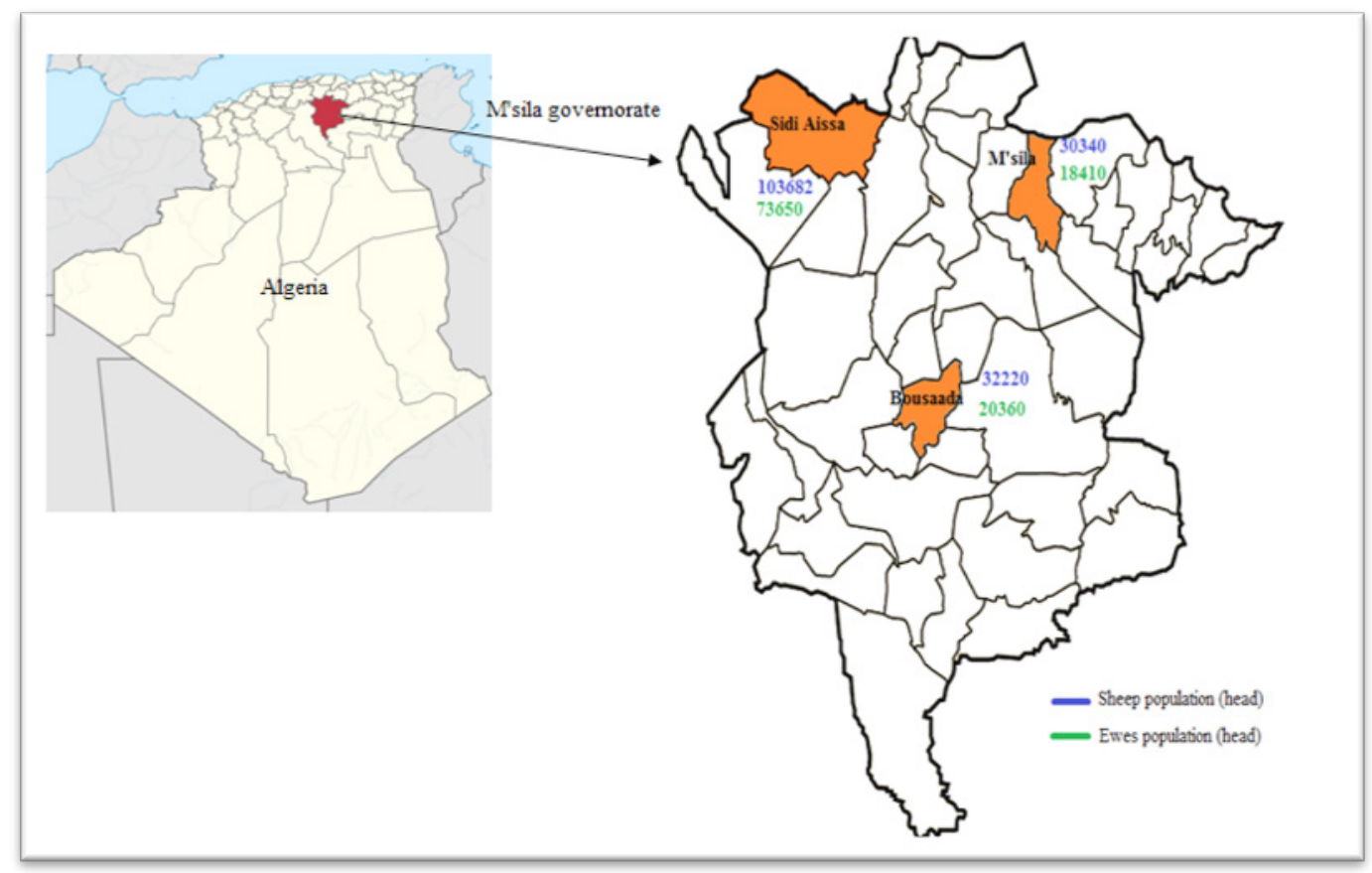

Figure 1. Map showing distribution of sheep flocks in study region (D.V.S of M'Sila governorate, 2018). 
two categories: light infection (single cyst or less than 10 cysts) and intense infection (more than 10 cysts). Types of cysts were determined according to the classification of Gharbi et al., (1981). Type 1: cyst with pure liquid collection, Type 2: cyst with liquid collection and a floating wall, Type 3: semicalcified cysts with a hard wall.

\section{Breeding conduct survey}

Additionally, to visceral inspection, another survey was conducted from March to April 2018, on a sample of 46 flocks located in M'Sila region in order to understand the real causes of this scourge using questionnaire and interviews. The questionnaire covered several risk factors for hydatidosis especially, presence of dogs in promiscuity with sheep, dogs deworming programs, presence of other animal species living in promiscuity with sheep, breeding and feeding methods, procedures implemented by breeders toward infected organs when sheep are slaughtered inside farms (informal slaughter).

\section{Statistical analyses}

The data processing was done by Microsoft Excel (2010) and statistical tests by Graph Pad Prism 7.00 Software. The statistical significance of each difference between the locations (hepatic, pulmonary) and types of hydatid cysts, and also between seasons, age and sex of the infested animals, were evaluated by Chi-square tests. One way ANOVA was used to determine the intensity of the infestation by comparing the number of cysts in the infested animals. A value of $p<0.05$ is considered as statistically significant.

\section{Results and discussions}

\section{Descriptive statistics. Frequency of} sheep hydatidosis in M'sila abattoirs

The table 1 shows the distribution of sheep slaughtered at three slaughterhouses in M'Sila region from December 2017 to April 2018. Among 9048 sheep slaughtered during the period of survey, there were 2244 sheep infested by $E$. granulosus giving thus a general rate of $24.80 \%$.

\section{Influence of age}

Results confirm that the highest prevalences are obtained from the age group (5-6 years). The lowest prevalences are observed at, Boussaâda abattoir in the age group of (1-2 years) $0.39 \%$, and at Sidi Aissa abattoir, $0.57 \%$ in the age group of 2-3years (Tab 2).

\section{Influence of sex}

Results statistical analysis show a predominance of hydatidosis cases in females $(\mathrm{p}<0.0001)$ with high rates, $97.19 \%$ for M'Sila abattoir, $98.24 \%$ for Boussaâda abattoir and $98.09 \%$ for Sidi Aissa abattoir (Tab. 2).

\section{Influence of the season}

Results presented on Table 2 show seasonal prevalence variations. The percentage of infested sheep shows slight difference in both seasons. Among 2244 cases of parasitized sheep; (63.06\%) are recorded in spring (season 2) which is higher compared to the rate registered during the winter (season 1,36.94\%) but this difference is not significative $(\mathrm{p}>0.05)$.

Table 1. Monthly prevalence of hydatidosis in slaughtered sheep in M'sila abattoirs

\begin{tabular}{lccc}
\hline Months & Slaughtered sheep & Infested sheep & $\mathbf{\%}$ \\
\hline Dec & 1429 & 234 & 16.38 \\
\hline Jan & 1625 & 296 & 18.26 \\
\hline Feb & 1758 & 299 & 17.01 \\
\hline Mar & 2088 & 475 & 22.75 \\
\hline April & 2148 & 940 & 43.76 \\
\hline Total & $\mathbf{9 0 4 8}$ & $\mathbf{2 2 4 4}$ & $\mathbf{2 4 . 8 0}$ \\
\hline
\end{tabular}




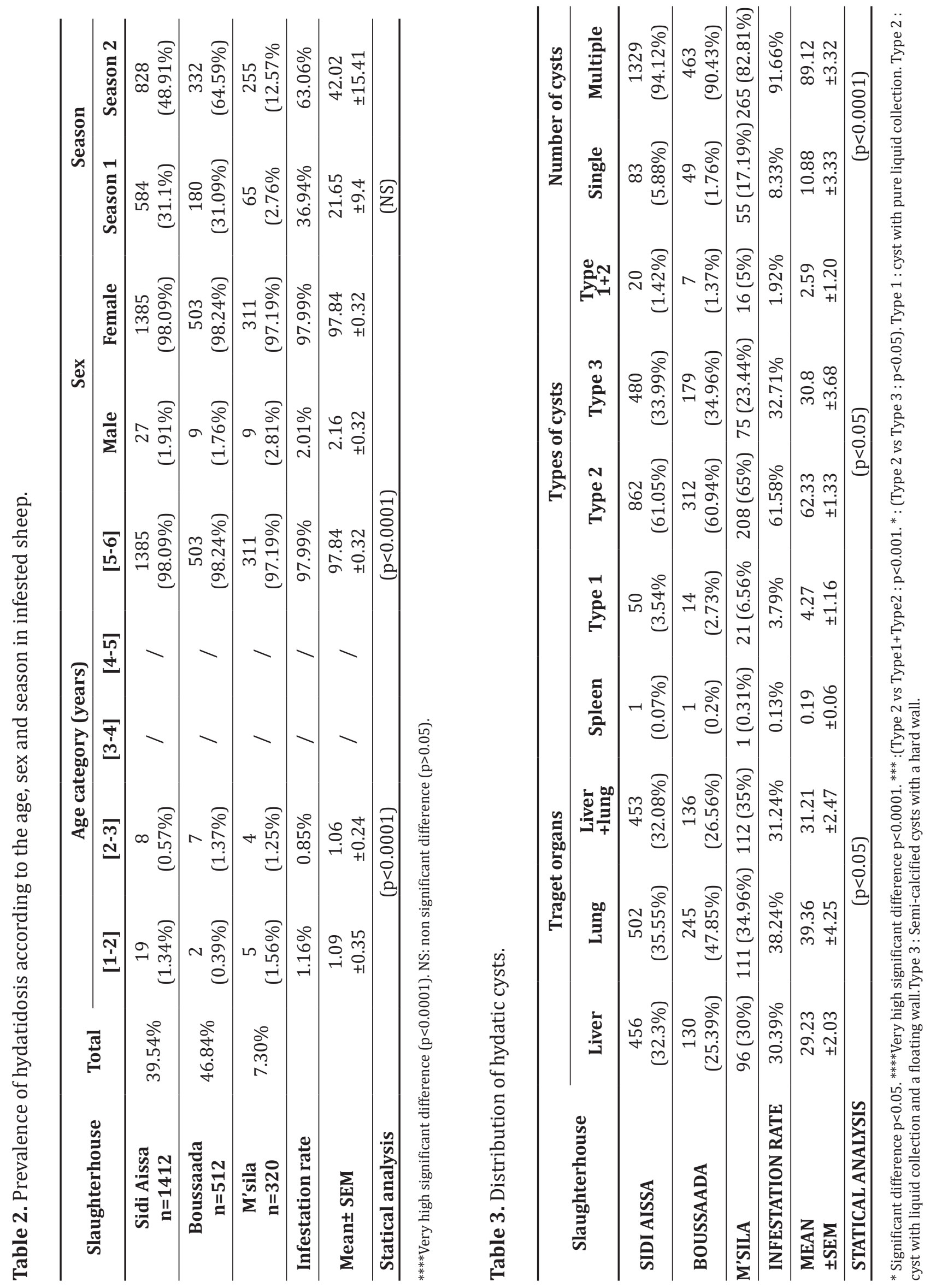




\section{Distribution of hydatic cysts} Distribution of hydatic cysts by location (target organs)

Results described in Table 3 show that the lung represents the first location of hydatic cysts in frequency alone in 245 and 502 cases (47.85 \% and $35.55 \%$ respectively at Boussaâda and Sidi Aissa abattoirs). At M'Sila slaughterhouse the location (liver and lungs) represents 35\%. The liver represents the second location in frequency alone $(32.3 \%)$ in the slaughterhouses of Boussaâda and Sidi Aissa. At M'Sila abattoir, it was recorded a predominance of pulmonary location with $34.69 \%$.

Distribution of hydatidosis by type of cysts

Results statistical analysis (Table 3 ) show the predominance $(\mathrm{p}<0.001)$ of liquid cysts with a floating membrane (Type 2) which occupy a very large part at the three visited slaughterhouses, M'Sila: 65\%, Boussaâda: $60.94 \%$ and Sidi Aissa: $61.05 \%$. While Type 3 of cysts (Semi-calcified cysts with a hard wall) presented percentages of $23.44 \%, 34.96 \%$ and $33.99 \%$ respectively as the former order.

\section{Distribution of hydatidosis by number of cysts}

Results show that the majority of infested sheep contain multiple cysts at the three slaughterhouses, M'Sila: $82.81 \%$, Boussaâda: 90.43\% and Sidi Aissa: 94.12\%. The single cyst cases rep- resent small percentages: $17.19 \%, 9.57 \%$ and $5.88 \%$ respectively as the former order (Table 3 ).

\section{Feeding methods}

In our study area, feeding is based mainly on pasture (100\% of flocks). $78.26 \%$ of breeders use straw as a food source. $84.78 \%$ feed animals with barley (Figure 2).

\section{Data collected through the questionnaire in the flocks.}

This survey was conducted from March to April of 2018 among 46 breeders in different municipalities in the M'sila region to examine several aspects that are related to the prevalence of hydatidosis, the population, presence of dogs and their deworming program, presence of other species of animals in the flocks, the environment and the farming methods.

\section{Presence of dogs in the flocks}

The presence of dogs in the flocks and their deworming program is a major risk factor in hydatidosis prevalence. Our results in the figure 3 show the close association between dogs and ruminants which plays an undeniable role in the transmission pattern. The majority of the breeders accompany the dogs with the herd or $95.65 \%$ in the farms or in pastures. $4.35 \%$ of the breeders surveyed to do not have dogs on farms. Note that, all breeders call the veterinarian, but do not care

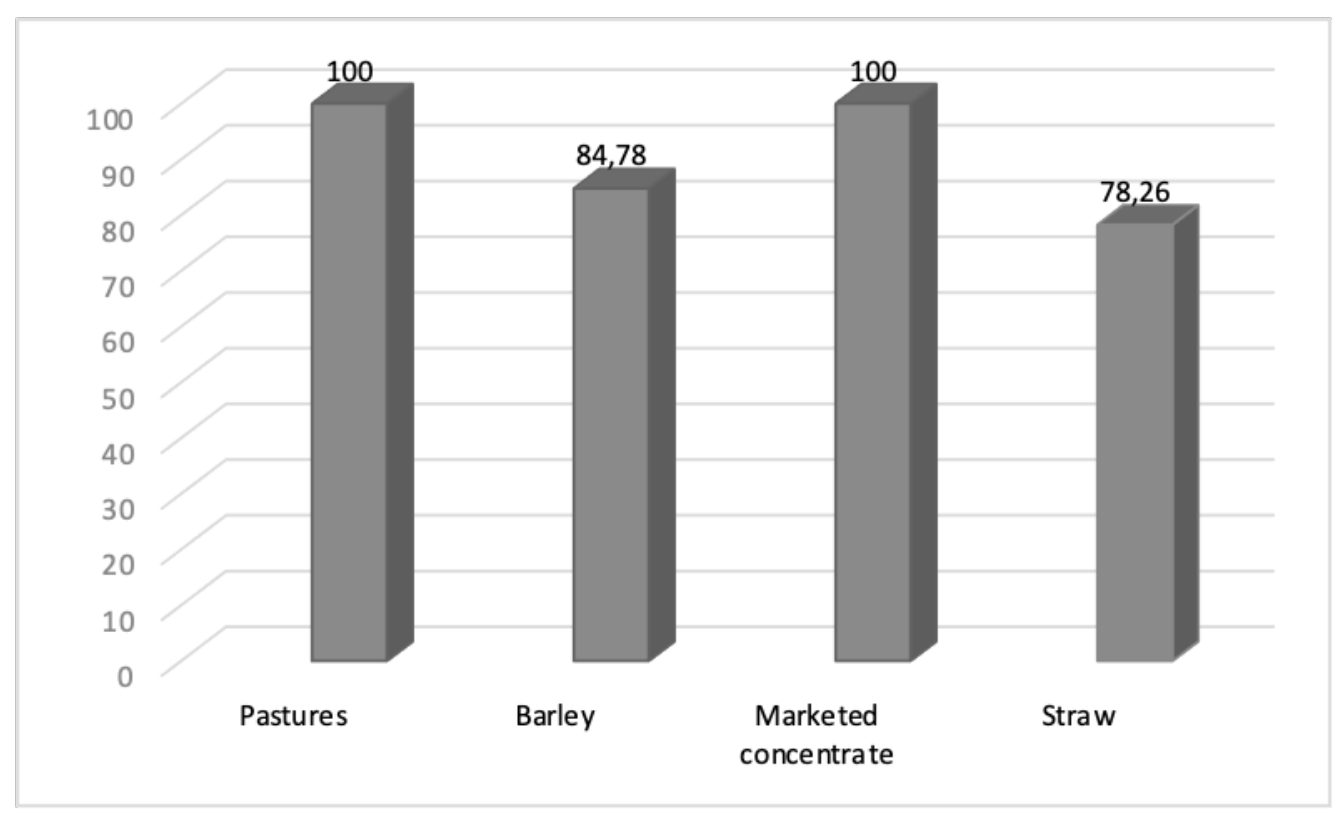

Figure 2. Feeding method used in sheep farming in the M'sila region 
about dewatering of dogs that are mixed with the herd.

\section{Presence of goats and cattle in the flocks}

The figure 4 show $t$ that the herd is always composed of a mixture of animals of different ages and sex. $50 \%$ of flocks are represented by the mixture between the sheep, goat and bovine species. $28.26 \%$ of breeders have a mixed herd of sheep and cattle, $15.22 \%$ of breeders have a mixed herd of sheep and goats and only three have a flock of sheep exclusively.

When comparing the obtained results with those of other countries, it was found that the current infestation rate by E. granulosus at M'Sila slaughterhouses, is significantly higher compared to the rate obtained Elmajdoub and Rahman (2014) in Libya and Miran et al., (2017) in Tanzania, which reported an infestation rate of $8.06 \%, 12.6 \%$ and $16.6 \%$ respectively. Furthermore, in Tunisia, by

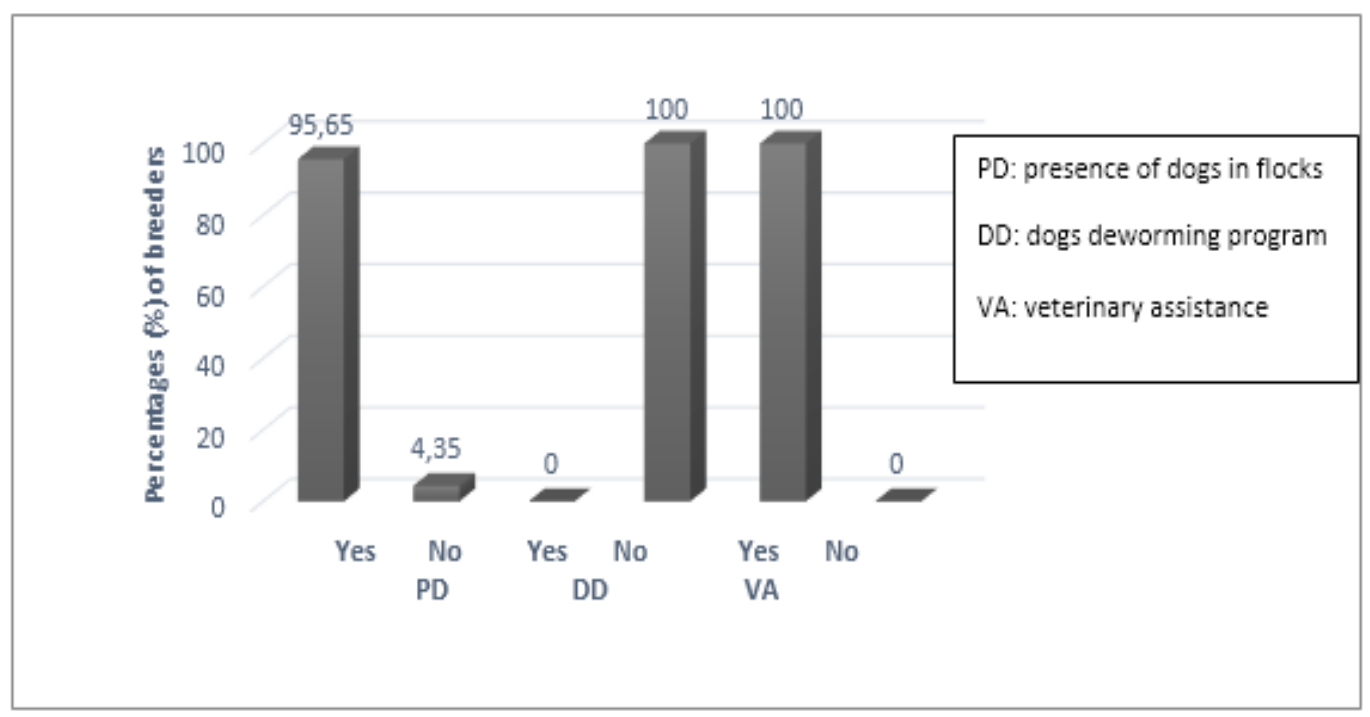

Figure 3. Presence of dogs and veterinary assistance in the visited flocks

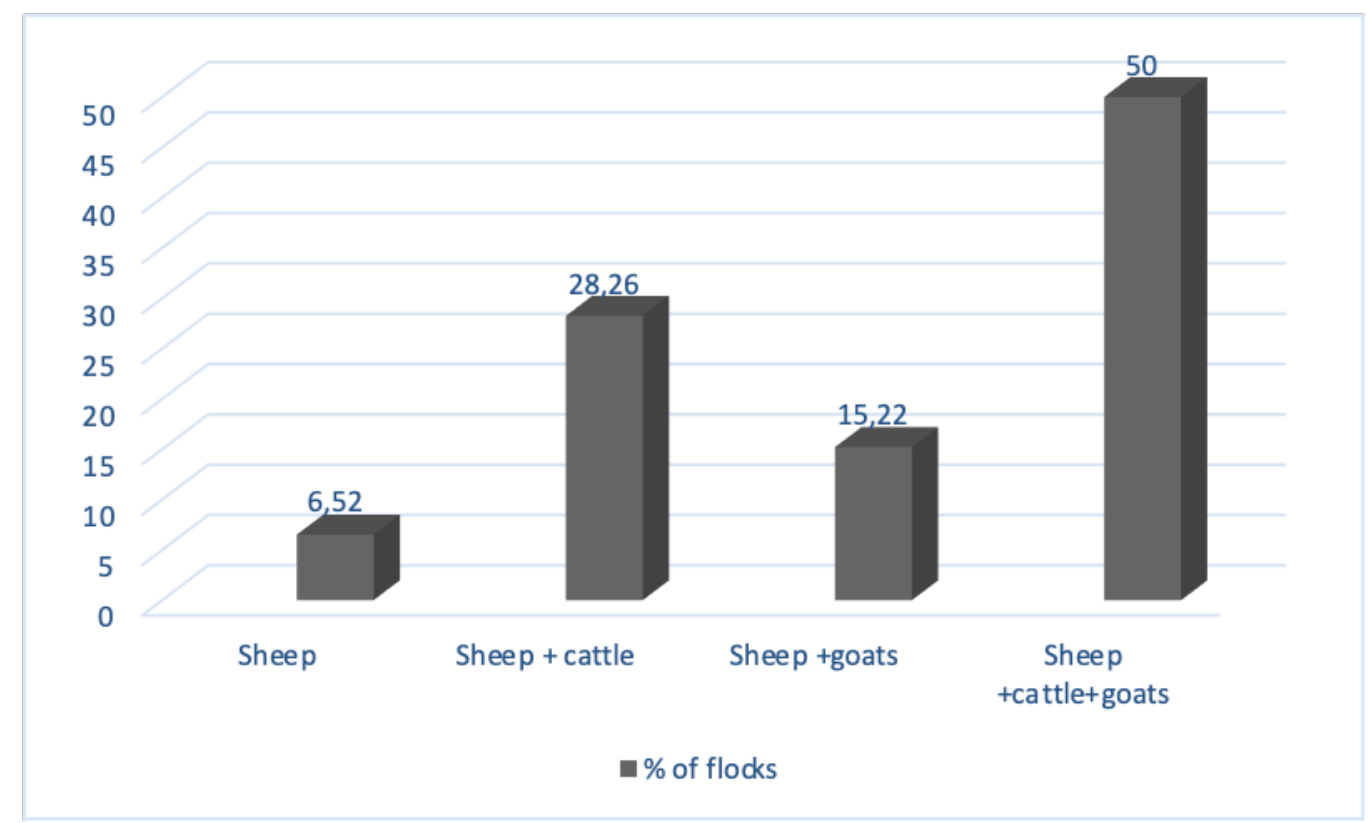

Figure 4. Animal's distribution in the flocks 
Lahmar et al., (2013); 16.42\% (447/2722). While, in another African country: Ethiopia, Getachew et al., (2012) reported a rate of 7.7\% (25/325), Shimeles and Awole (2018) reported infestation rate of $7.04 \%(27 / 384)$.

In Asia, Jarjees and Al-Bakri (2012) reported a prevalence of $2 \%(96 / 4800)$ for Iraqi sheep. However, it was important to mention that the recorded prevalence of E. granulosus at M'sila dominant abattoirs, is much lower than that reported for Sardinia by Scala et al., 2006, 75\% (580/771) and for Peru by Dueger and Gilman (2001), 77.4\% (164/212).

According to Traub et al. (2005), Buishi et al. (2006) and Varcasia et al. (2011), the major risk factors of human and animal hydatidosis in the interviewed households were: lack of domestic dogs deworming, sheep grazing on wild plants, practices related to the informal family slaughter of sheep (place of slaughter, age of slaughtered sheep, post-slaughter waste management) and the existence of clandestine slaughterhouses, all these factors increase the frequency of the disease.

As presented on Table 2, the percentage of affected sheep slaughtered during spring, is higher compared to those slaughtered in winter but this observation is not statically significant ( $p>0.05)$. Prevalence of ovine hydatidosis is directly influenced by sheep breeding conduct through the permanent use of pastures contaminated by parasites eggs, especially in spring. Also, rainfall is more frequent in spring, which contributes in the persistence of an adequate environment for preservation and development of embryo eggs deposited on plants and soils which were highly contaminated by dog's feces. These suggestions are confirmed in the current study by the results of surveys carried out on the flocks in M'Sila region (as shown in the figure 2: throughout the year the breeders are dependent on the extensive system when feeding is based mainly on pasture " $100 \%$ of flocks"). According to Getachew et al., (2012), the seasonal variation in prevalence rate of E. granulosus, could be associated with different factors such as; temperature change, environmental conditions and rearing patterns. Aminzare et al., (2018), recorded that the highest seasonal prevalence of hydatidosis especially lung form was seen in autumn and winter seasons.

Concerning slaughtered animals from different abattoirs of M'sila governorate, it was found that female's sheep were the most affected by hydatidosis (97.99\%), while the prevalence in males was only $2.01 \%$ (table 3 ). In a study conducted in Riadh city in Saudi Arabia, Almalki et al. (2017) reported a high rate of hydatic cyst infestation in young males compared to females. This finding could be explained by the high number of males killed in favour of strict enforcement of the current regulations, which prohibits the slaughter of female animals, except on a certificate issued by a veterinarian after examination of the animal, giving consequently more chance of detecting the hydatic cyst in males than in females, who are only killed at a very advanced age. For our study region, despite Algerian legislation forbids the slaughter of fertile females with exceptions to some pathological or reform cases, it is not sure that these laws are rigorously applicable in whole national abattoirs. Muqbil et al. (2012) reported that female infestation is 6.75 times higher than male infestation, at $2.7 \%$ and $0.4 \%$ respectively.

Results of the current study demonstrate a high prevalence of hydatidosis in sheep aged more than 5 years (table 4). According to Almalki et al. (2017), in Saudi Arabia, the infection differed according to the sheep's age, with the highest prevalence in sheep aged between 6 and 12 months (58.2\%) followed by sheep aged between 13 and 24 months (30.6\%) while the lowest prevalence was in sheep aged more than 2 years (11.2\%). In concordance with our study results, for China, Yang et al. (2015) report that there is a significant association between host age and hydatic cyst infestation and adults are more likely to develop hydatic cysts than young sheep. According to Gebreyohannes and Wondie (2014), this difference in the prevalence between older and younger animals could be mainly due to longer exposure time to Echinococcus eggs.

Nyero et al., (2015), Yang et al. (2015), Razi et al. (2017) and Abo-Aziza et al. (2019) report that there is a significant association between host age and hydatic cyst infestation and adults are more likely to develop hydatic cysts than young sheep. However, Shimeles and Awole (2018) found that no significant differences were recorded between young and adult ruminants in the number of cysts and prevalence based on age.

In the current study (table 3), the prevalence of hydatic cysts in lungs was higher than that recorded for livers and spleen $(\mathrm{p}<0.05)$. Our results 
are similar to those of Azami et al. (2013), Elmajdoub and Rahman (2014) and Mirzaei et al. (2015) who reported that the hydatic cyst in the lung is more common than that in the liver.

In addition, the work of Hamrat et al. (2013) shows that lung infestation predominates in most regions of Algeria during the years 2007 to 2010. The migration path of embryophores could explain the predominance of pulmonary and hepatic localizations. In fact, they are released into the intestinal light, pass through the intestinal wall thanks to their hooks and then gain blood circulation. In this migration, they encounter two essential filters, the liver and the lungs. The literature reveals that in older ruminants, sinusoid capillaries in the liver allow embryophors to pass into the lungs. It is also possible that embryophores enter the hepatic circulation and eagerly the thoracic ducts to the lung, which may be infested before the liver. Jarjees and Al Bakri (2012), Almalki et al. (2017), reported an increase in the liver location of hydatic cysts compared to the pulmonary one.

Our finding is also in concordance with that reported in Ethiopia (Getachew et al., 2012), who reported $60 \%$ and $36 \%$ for lung and liver localizations respectively. In the same country, Fromsa and Jobre (2011) reported prevalences of lung and liver localizations of $8.15 \%$ and $7.41 \%$, respectively. In Peru, infestation rates of $22 \%$ and $6.7 \%$ for lung and liver respectively, were reported by Eckert and Deplazes (2004).

In the present study, $61.58 \%$ of the slaughtered animals present multiple cysts cyst with liquid collection and a floating membrane, while $32.71 \%$ present semi-calcified cysts with a hard wall (Table 3). Comparatively, in Sardinia, a study shows that out of the 5295 identified cysts; 2376 were calcified (45\%), 1644 liquid (31\%) and 1275 caseous (24\%). The calcified, liquid and caseous cysts, were present in 254,109 and 191 of the ewes, respectively, representing thus, $63.7 \%, 27.3 \%$ and $47.9 \%$, respectively, of the ewes inspected (Scala et al., 2006). Another factor involved in the parasite's transmission dynamics is the intensity of the infection (estimated by number of cysts when more than $80 \%$ of infested animals present multiple cysts "more than 10 cysts") and cyst evolution stage. A calcified or caseous cyst no longer contains infectious protoscolex and therefore it no longer plays a role in parasite transmission. How- ever, liquid cysts are more likely to contain these infectious protoscolex. Each protoscolex has the ability to contaminate a definitive host and thus continue the cycle.

Hydatidosis is an endemic parasitic disease, which is widespread in many countries that have in common a number of risk factors that may explain the frequency of this disease, particularly; density of sheep breeding (figure 1) and mixture of flocks (50\% of flocks are represented by the mixture between the sheep, goat and bovine species (figure 4), the number and health status of guard dogs (figure 3), the humidity conducive to the care of embryophores in the outdoor environment to which insufficient hygiene rules are added.

\section{Conclusion}

Our study showed a high rate of hydatidosis infection in slaughtered sheep and may alarm society and authorities to the widespread of disease in ruminants of other parts of Algeria. Since sheep are infested mainly in pastures, by ingestion of vegetations contaminated with feces of parasitized dogs, it is essential to highlight according to our field investigation, the existing insufficient control of infection in the definitive host (guard dogs), the unlimited number of abandoned or uncontrolled dogs and eventually of wild canids living in promiscuity of sheep flocks and slaughterhouses which would increase the risk of hydatidosis widespread.

Acknowledgments. The authors would like to thank the Directory and administrative staffs of M'Sila slaughterhouses (M'Sila, Bousaâda and Sidi Aissa) for support while doing autopsy and diagnose and facilitating study.

Conflict of interest statement. The authors declare that they have no conflict of interest.

\section{References}

1. Abo-Aziza FAM, Oda SS, Aboelsoued D, Farag TK, Almuzaini AM (2019). Variabilities of hydatidosis in domestic animals slaughtered at Cairo and Giza abattoirs, Egypt. Veterinary World, EISSN: 2231-0916 vol 12

2. Almalki E, Al-Quarishy S, Abdel-Baki AS (2017). Assessment of prevalence of hydatidosis in slaughtered Sawakny sheep in Riyadh city, Saudi Arabia. Saudi Journal of Biological Sciences, 24, 1534-1537.doi:10.1016/j. sjbs.2017.01.056.

3. Aminzare M, Hashemi M, Yaghoobi Faz S, Raeisi M, Hassanzadazar H. (2018). Prevalence of liver flukes 
infections and hydatidosis in slaughtered sheep and goats in Nishapour, Khorasan Razavi, Iran. Veterinary World, EISSN: 2231-0916.

4. Azami M, Anvarinejad M, Ezatpour B, Alirezaei M (2013). Prevalence of hydatidosis in slaughtered animals in Iran. Turkiye Parazitol Derg, 37,102-106. doi:10.5152/ tpd.2013.24.

5. Buishi IE, Njoroge EM, Bouamra O, Craig PS (2006). Canine echinococcosis in northwest Libya: Assessment of coproantigen ELISA, and a survey of infection with analysis of risk factors". Veterinary Parasitology, 130, 223232. doi:10.1016/j.vetpar.2005.03.004.

6. Craig P, Mastin A, Kesteren FV, Boufana B (2015). Echinococcus granulosus: Epidemiology and state-of-theart of diagnostics in animals. Veterinary Parasitology, 213,132-148. doi :10.1016/j.vetpar.2015.07.028.

7. Directory of Veterinary Services of M'Sila governorate (D.V.S) (2018). Statistical report on sheep flocks in M'Sila governorate.

8. Dueger EL, Gilman RH (2001). Prevalence, intensity, and fertility of ovine cystic echinococcosis in the central Peruvian Andes". Transactions of the royal society of tropical medicine and hygiene, 95 (4), 379-383. doi: 10.1016/S0035-9203 (01) 90188-9.

9. Eckert J, Deplazes P (2004). Biological, epidemiological, and clinical aspects of echinococcosis, a zoonosis of increasing concern. Clin. Microbiol. Rev., 17, 107-135. doi:10.1128/cmr.17.1.107-135.2004.

10. Elmajdoub LO, Rahman, WA (2014). Prevalence of Hydatid Cysts in Slaughtered Animals from Different Areas of Libya. J Veter Sci Med 2, 2.

11. Fromsa A, Jobre Y (2011). Infection prevalence of hydatidosis (Echinococcus granulosus Batsch, 1786) in domestic animals in Ethiopia: A synthesis report of previous surveys, Ethiopian Veterinary Journal, 15, 11-33.

12. Gebreyohannes M, Wondie M (2014). Hydatidosis: Prevalence and economic significance in cattle slaughtered at Diredawa municipal abattoir, Ethiopia. Int. J. Agro.Vet. Med. Sci., 8(3): 64-80

13. Gharbi HA, Hassine W, Brauner MW, Dupuch K (1981). Ultrasound examination of the hydatic liver. Radiology; 139(2):459-463.

14. Getachew D, Almaw G, Getachew T (2012). Occurrence and fertility rates of hydatid cysts in sheep and goats slaughtered at Modjo Luna Export Slaughterhouse, Ethiopia, EthiopianVeterinary Journal,16 (1), 83-91.

15. Hayajneh FMF, Althomali AMH, Nasr ATM (2014). Prevalence and characterization of hydatidosis in animals slaughtered at Al Taif abattoir, Kingdom of Saudi Arabia. Open Journal of Animal Sciences, 4, 38- 41. doi:10.4236/ ojas.2014.41006.

16. Jarjees MT, Al-Bakri HS (2012). Incidence of hydatidosis in slaughtered livestock at Mosul, Iraq. Iraqi Journal of Veterinary Sciences, 26 (1), 21-25. Available on: http:// www.vetmedmosul.org/ijvs.

17. Lahmar S, Trifi M, Naceur SB, Bouchhima T, Lahouar N, Lamouchi I, Maâmouri N, Selmi R, Dhibi M, Torgerson PR (2013). Cystic echinococcosis in slaughtered domestic ruminants from Tunisia. Journal of Helminthology, 87(03), 318-325.doi: 10.1017/S0022149X12000430.

18. Melaku A, Lukas B, Bogale B (2012). Cyst Viability, organ distribution and financial losses due to hydatidosis in cattle slaughtered at Dessie Municipal Abattoir, Northeastern Ethiopia. Veterinary World, 5(4), 213-218. doi: 10.5455/vetworld.2012.213-218.

19. Miran MB, Kasuku AA, Swai ES (2017). Prevalence of echinococcosis and Taenia hydatigena cysticercosis in slaughtered small ruminants at the livestock-wildlife interface areas of Ngorongoro, Tanzania. Veterinary World, EISSN: 2231-0916.

20. MirzaeiM,RezaeiH,NematollahiA(2015).Roleofruminants in the epidemiology of Echinococcus granulosus in Tabriz area, Northwest of Iran. Tropical Biomedicine 32(2): 269275.

21. Muqbil NA, Obad M, Al-salamiand Hiam A, Arab H (2012). Prevalence of Unilocular Hydatidosis in Slaughtered Animals in Aden Governorate-Yemen. Jordan Journal of Biological Sciences.5 (2): 121 - 124.

22. NyeroD,ZirintundaG,OmadangL,EkouJ(2015).Prevalence of hydatid cysts in goats and sheep slaughtered in Soroti Municipal Abattoir, Eastern Uganda. African Journal of Parasitology Research ISSN 2343-6549 Vol. 2 (9), pp. 148151.

23. Razi Jalali MH, Ahmadiara E, Rahimzade A, Shekarian MH, Javidi Dasht-bayaz J, Jamshidi L, Nikpay A (2017). Prevalence, Fertility, and Viability Rates of Hydatid Cysts in Surgical Patients and Slaughtered Small Ruminants in Ahvaz, Southwest of Iran. Journal of Food Quality and Hazards Control 4: 49-52.

24. Romig T, Ebi D, Wassermann M (2015). Taxonomy and molecular epidemiology of Echinococcus granulosus sensu lato. Veterinary Parasitology, 213, 76-84. doi: 10.1016/j. vetpar.2015.07.035.

25. Scala A, Garripa VA, Tranquillo VM, Genchi C (2006). Cystic echinococcosis in slaughtered sheep in Sardinia (Italy). Veterinary Parasitology, 135 (1), 33 - 38. doi:10.1016/j. vetpar.2005.08.006.

26. Shimeles A, Awole M (2018) Crossectional study on the prevalence and economic significance of hydatidosis in slaughtered ruminants at Debre Zeit Elfora export abattoir Oromia region eastern Showa zone, Ethiopia. Biomed. J. Sci. Tech. Res., 3(3): 1-9.

27. Thompson RC, Mc Manus DP (2002). Towards a taxonomic revision of the genus Echinococcus. Trends in Parasitology, 18, 452-457. Available on PMID :12377596.

28. Traub RJ, Robertson ID, Irwin PJ, Mencke N, Thompson A (2005). Canine gastrointestinal parasitic zoonoses in India. Trends in Parasitology, 21 (1), 42 - 48. doi:10.1016/j. pt.2004.10.011.

29. Varcasia A, Tanda B, Giobbe M, Solinas C, Pipia AP, Malgor R, Carmona C, Garippa, G, Scala A (2011). Cystic echinococcosis in Sardinia: farmers' knowledge and dog infection in sheep farms. Veterinary Parasitology, 181, 335-340. doi: 10.1016/j.vetpar.2011.05.006.

30. WHO (2011). Report of the WHO informal working group on cystic and alveolar echinococcosis surveillance, prevention and control, with the participa- 
tion of the Food and Agriculture Organization of the United Nations and the World Organization for Animal Health (Geneva, Switzerland, World Health Organization). ISBN: 97892 41502924WHO/HTM NTD/ NZD/2011.2.Available on: http://apps.who.int/iris/bitst ream/10665/44785/1/9789241502924_eng.pdf?ua=1.
31. Yang S, Wu W, Tian T, Zhao J, Chen K, Wang Q Feng, Z (2015). Prevalence of Cystic Echinococcosis in slaughtered sheep as an indicator to assess control progress in Emin Counrty, Xinjiang, China. Korean Journal of Parasitology, 53(3), 355-359. doi:10.3347\%2Fkjp.2015.53.3.355. 